\title{
Efficacy of early chick nutrition with Aloe vera and Azadirachta indica on gut health and histomorphometry in chicks
}

\author{
Tamilvanan Sujatha, Sivasankar Abhinaya, Jai Sunder, Marudhai Thangapandian and Anandamoy Kundu \\ Division of Animal Science, ICAR-Central Island Agricultural Research Institute, Port Blair - 744 105, \\ Andaman and Nicobar Islands, India. \\ Corresponding author: Tamilvanan Sujatha, e-mail: drsujathaars@rediffmail.com,
}

Co-authors: SA: abislaw3@gmail.com, JS: jaisunder@rediffmail.com, MT: sugigold@gmail.com, AK: drakundu1@yahoo.co.in Received: 28-10-2016, Accepted: 13-04-2017, Published online: 01-06-2017

doi: 10.14202/vetworld.2017.569-573 How to cite this article: Sujatha T, Abhinaya S, Sunder J, Thangapandian M, Kundu A (2017) Efficacy of early chick nutrition with Aloe vera and Azadirachta indica on gut health and histomorphometry in chicks, Veterinary World, 10(6): 569-573.

\begin{abstract}
Aim: This study was conducted with an aim of studying the efficacy of water supplements of Aloe vera and Azadirachta indica (neem) during pre-starter age (0-2 weeks) on gut health and histomorphometry in Vanaraja chicks.

Materials and Methods: A total of 192 day old Vanaraja chicks were randomly assigned to one of four herbal water treatments throughout the experimental pre-starter stage (0-2 weeks) in a completely randomized design. Each treatment was given four replicates consisting of 12 chicks per replicate. Water treatments comprised T1: Control with regular antibiotic supplement, T2: $3 \mathrm{ml}$ Aloe juice per chick per day, T3: $3 \mathrm{ml}$ neem extract per chick per day, T4: $1.5 \mathrm{ml}$ Aloe and $1.5 \mathrm{ml}$ neem per chick per day. Gut culture was done for Escherichia coli and Lactobacillus sps. and gut histomorphometry in 24 gut samples at 14 days of age.

Results: This study revealed that supplementation of $A$. vera and neem in water significantly $(\mathrm{p}<0.05)$ reduced and increased the number of gut E. coli and Lactobacillus sps. Colonies, respectively, as compared to that of control groups; Villi was significantly $(\mathrm{p}<0.05)$ taller and broader on 14 days of age across the jejunum of chicks fed with neem supplementation as compared to that of control chicks. Significantly lower crypt depth $(\mathrm{p}<0.05)$ was observed in the duodenum of Aloe supplementation. Villus height: Crypt depth ratio of duodenum and jejunum was significantly $(\mathrm{p}<0.05)$ increased neem and Aloe supplementation in chicks as compared to their combination and control.
\end{abstract}

Conclusion: Immediate post hatch supplementation of Aloe juice and neem extract in chicks improved the development and health of their gut.

Keywords: Aloe vera, Azadirachta indica, chicks, early chick feeding, gut health, histomorphometry.

\section{Introduction}

Early chick nutrition, commonly termed as prestarter feeding helps in utilization of yolk sac for optimal immunity and gut development and to enhance its function. Early chick feeding has a great potential to trigger the gut and its morphological development for improved performance and better feed conversion ratio $[1,2]$. Hence, studies on the effect of early chick nutrition on gut health and morphology are having great importance in poultry. Since the start of organized poultry industry, antimicrobials have been used as feed and water supplement in poultry feed to enhance the gut development and growth performance. However, due to emergence of multiple drug resistant bacteria [3] by the use of antibiotics at sub-therapeutic level, pre and probiotics, herbs, spices and various medicinal plant extracts are being given more attention as possible antibiotic growth promoter replacement [4].

Copyright: Sujatha, et al. Open Access. This article is distributed under the terms of the Creative Commons Attribution 4.0 International License (http://creativecommons.org/licenses/ by/4.0/), which permits unrestricted use, distribution, and reproduction in any medium, provided you give appropriate credit to the original author(s) and the source, provide a link to the Creative Commons license, and indicate if changes were made. The Creative Commons Public Domain Dedication waiver (http:// creativecommons.org/publicdomain/zero/1.0/) applies to the data made available in this article, unless otherwise stated.
Medicinal plants have an indispensable source of medicine for poultry production systems since ancient times. A significant number of farmers are still judiciously using herbal remedies in the management of rural poultry in spite of modern veterinary treatment. As per the estimation of WHO, even today $80 \%$ of people still rely on medicinal plants [5] for their livestock treatment. Studies on the use of phytogenic feed additives as growth promoters and immune enhancers in broiler nutrition are numerous. Aloe vera has a rich source for many chemical compounds and plays various roles in animal system. Similarly, Azadirachta indica (neem) leaves have vast properties such as as immune modulatory, anti-inflammatory, antihyperglycemic, antimalarial, antifungal, antibacterial, antiviral, antioxidant, antimutagenic, and anticarcinogenic [6-8]. Neem plays an important role enhancing growth owing to antibacterial and hepatoprotective properties [7]. However, work on effect of early chick nutrition with Aloe and neem juice on gut histomorphology is limited.

The morphology of intestinal villi and crypts has been associated in chickens with intestinal function and growth. Adverse changes in the content of the digesta, such as high population of pathogenic bacteria, parasites or substances, could lead to changes 
in the surface of intestinal mucosa, because of their close proximity. Hence, the aim of this work is to study the efficacy of water supplementation of $A$. vera and $A$. indica during pre-starter age ( $0-2$ weeks) on gut histomorphometry of Vanaraja chicks.

\section{Materials and Methods}

\section{Ethical approval}

The experiment was conducted after the permission of Institutional Animal Ethics Committee of ICAR-Central Island Agricultural Research Institute, Port Blair.

\section{Sample preparation and experimental design}

$A$. vera and $A$. indica (neem) were freshly collected for the study. A. vera juice was prepared by grinding the pulp without water, filtering and mixing with water at 1:1 ratio; $200 \mathrm{~g}$ of neem leaves in $1 \mathrm{~L}$ of water was kept in shaking water bath for overnight for extraction and was filtered in the morning. The pre-starter feed was prepared with $20 \%$ crude protein and $2800 \mathrm{kcal} \mathrm{ME} / \mathrm{kg}$ as per BIS (2007) recommendation and fed ad libitum to the experimental chicks. A total of 192-day-old Vanaraja chicks were randomly assigned to one of four herbal water treatments throughout the experimental pre-starter stage (0-2 weeks) in a completely randomized design. Each treatment was given four replicates consisting of 12 chicks per replicate. Water treatments comprised T1: Control with regular antibiotic supplement, T2: $3 \mathrm{ml}$ Aloe juice per chick per day, T3: $3 \mathrm{ml}$ neem extract per chick per day, T4: $1.5 \mathrm{ml}$ Aloe juice and $1.5 \mathrm{ml}$ neem extract per chick per day.

\section{Data collection}

Tissue samples from duodenum, jejunum and ileum and internal contents of intestine and ceca were collected from six Vanaraja birds by slaughtering, from each treatment by humane method at $14^{\text {th }}$ day of age. The gut contents were cultured for Escherichia coli and Lactobacillus sps. in nutrient broth and MacConkey Rogosa (MRS) broth, respectively, and identified using specific respective medias of eosine methylene blue and MRS agar. The microbial counts were determined as colony forming units per gram of samples ( $\mathrm{n}=6$ per treatment). The histomorphological study of tissue samples ( $\mathrm{n}=6$ per treatment and 6 fields per sample) was carried out according to the method described by Bancroft and Marilyn [9]. The data generated out of observations were subjected to statistical analysis as per Petrie and Watson [10]. The significance of the difference among the groups was determined by Duncan's multiple range tests [11].

\section{Results}

Effect of Aloe and neem water additives on gut microflora

Present experiment showed that supplementation of $A$. vera and neem in water significantly $(\mathrm{p}<0.05)$ reduced and increased the number of gut $E$. coli and Lactobacillus sps. colonies, respectively, as compared to the control (Table-1).

Effect of Aloe and neem water additives on histomorphological parameters of the gut villi in Vanaraja chicks

Villus height, width, and depth in the different segments of the small intestine of vanaraja chicks fed with Aloe and neem is shown in Table-2 and Plate-1. Histomorphometry of villi were significantly influenced by herbal supplementation. The significantly higher $(p<0.05)$ villi was seen in jejunum and illeum when neem was supplemented and that was statistically comparable with Aloe supplementation in duodenum and with Aloe plus neem supplementation in illeum, whereas there was significantly lower villi seen when chicks fed without any supplementation. However, there was no significant difference in villi height of duodenum, jejunum and ileum with Aloe plus neem supplementation as compared to the control.

With regard to villi width, significantly $(p<0.05)$ broader width was recorded in jejunum at $14^{\text {th }}$ day of supplementation with neem as compared to control and was statistically comparable with other herbal supplementation among which neem supplementation had induced significantly broadest villi. There were no significant differences in villi width of duodenum and illium between herbal supplementation and control.

Significantly $(\mathrm{p}<0.05)$ lower crypt depth was seen with neem and Aloe and Aloe plus neem supplementation as compared to control. Significantly lower crypt depth $(\mathrm{p}<0.05)$ was observed in the duodenum when the Aloe was supplemented as compared to neem and Aloe plus neem supplementation. Water supplementation of Aloe, neem and their combination did not result in significant differences in the crypt depth of jejunum segment. Villus height: Crypt depth ratio of duodenum and jejunum was significantly $(\mathrm{p}<0.05)$ increased at 14 days of neem and Aloe supplementation in chicks as compared to their combination and control. Small lumen and epithelium (Plate-1) were observed in the intestinal glands attached to the villi

Table-1: Effect Aloe and neem water additives on gut microbes in Vanaraja chicks.

\begin{tabular}{|c|c|c|c|c|}
\hline \multirow[t]{2}{*}{ Treatments } & \multicolumn{2}{|c|}{ Intestine } & \multicolumn{2}{|c|}{ Cecum } \\
\hline & Lactobacillus sps. & E. coli & Lactobacillus sps. & E. coli \\
\hline Control & $4.06^{\mathrm{c}} \times 10^{10}$ & $39.6^{\mathrm{a}} \times 10^{10}$ & $14.9^{c} \times 10^{10}$ & $93.5^{\mathrm{a}} \times 10^{10}$ \\
\hline Aloe & $9.36^{\mathrm{a}} \times 10^{10}$ & $4.07^{b} \times 10^{10}$ & $31.8^{\mathrm{ab}} \times 10^{10}$ & $38.6^{\mathrm{b}} \times 10^{10}$ \\
\hline Neem & $10.36^{\mathrm{a}} \times 10^{10}$ & $0.72^{c} \times 10^{10}$ & $47^{b} \times 10^{10}$ & $21.65^{c} \times 10^{10}$ \\
\hline Aloe+neem & $5.38^{b} \times 10^{10}$ & $2.6^{b} \times 10^{10}$ & $60^{\mathrm{a}} \times 10^{10}$ & $14.68^{d} \times 10^{10}$ \\
\hline
\end{tabular}

E. coli=Escherichia coli 


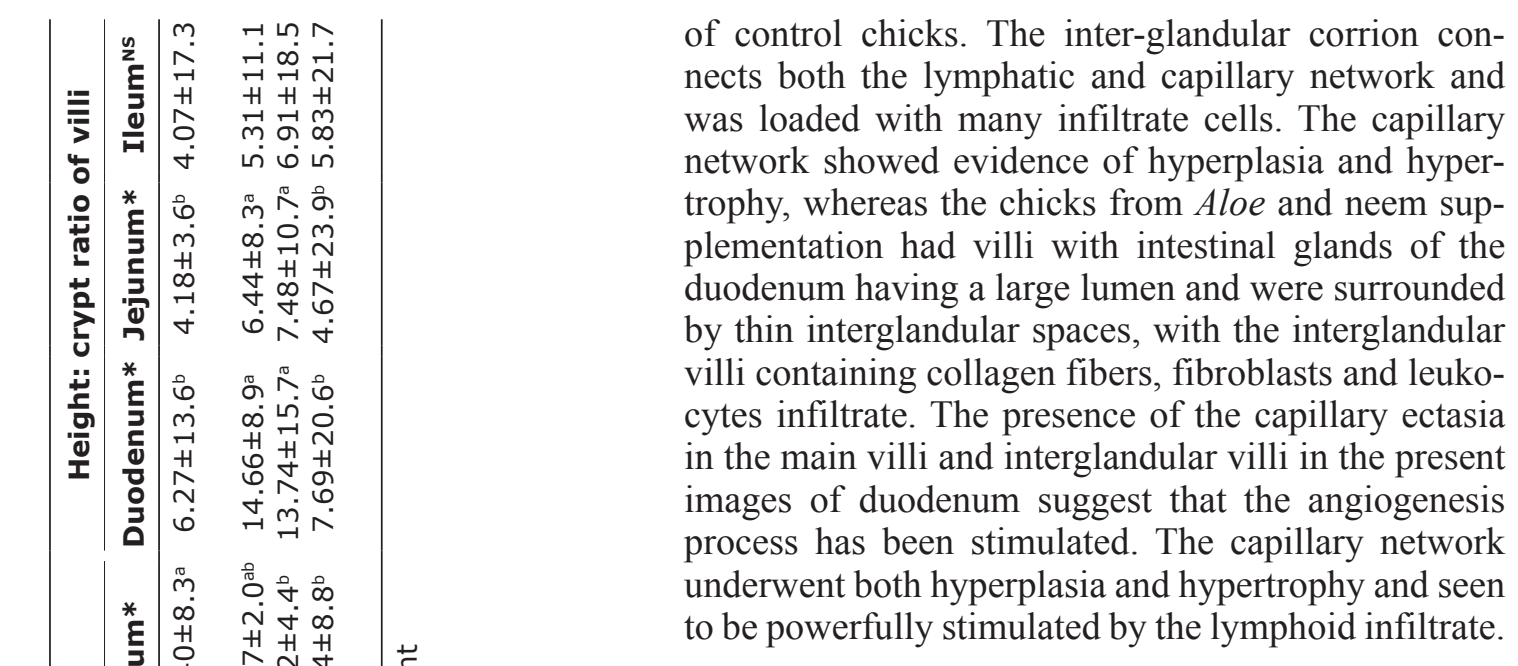

Discussion

Effect Aloe and neem water additives on gut microbes in vanaraja chicks

The microbial population in the gastrointestinal tract of poultry plays an important role in normal digestive processes and health maintenance [12]. This microbial shift might be due to the presence of huge numbers of chemically diverse and biologically active ingredients [13] in neem and acemannan, the polysaccharides in A. vera [14]. The results are in agreement with Mohammadmehdi and Jamshid [15] who also reported increased Lactobacillus spp. and reduced $E$. coli count through supplementing the feed with A. vera gel and Poonam et al. [16] as well recorded broad spectrum antibacterial effect with neem leave extract. Our findings are in accordance with reports that medicinal plants as alternatives to antibiotics exhibit the direct or indirect effects on intestinal microflora in poultry. This might be due to establishment of beneficial Lactobacillus sps. in that intestine. The final fermentation product of Lactobacillus sps. is lactic acid that might has made the gut environment unfavorable for pathogens and modified harmful microbial population.

Effect Aloe and neem water additives on gut histomorphometry in Vanaraja chicks

It was observed that neem and Aloe supplementation significantly $(p<0.05)$ improved the height of villi in duodenum, jejunum and ileum (Plate-1 and Table-2) while significant effect of Aloe plus neem could not be observed as compared to control. Among Aloe and neem supplementation, neem significantly improved both height and width of villi in jejunum. Except jejunum region, neem and Aloe supplementation did not significantly influence the width of villi in duodenum and ileum. Crypt depth were $(\mathrm{p}<0.05)$ significantly reduced by Aloe and neem supplementation in duodenum and ileum except jejunum. Significantly higher villi and lower crypt depth increased their ratio in the duodenum and jejunum of chicks fed with Aloe and neem extract. Water supplementation of Aloe, neem and its combination did not bring out any significant differences in the villi height and depth ratio 


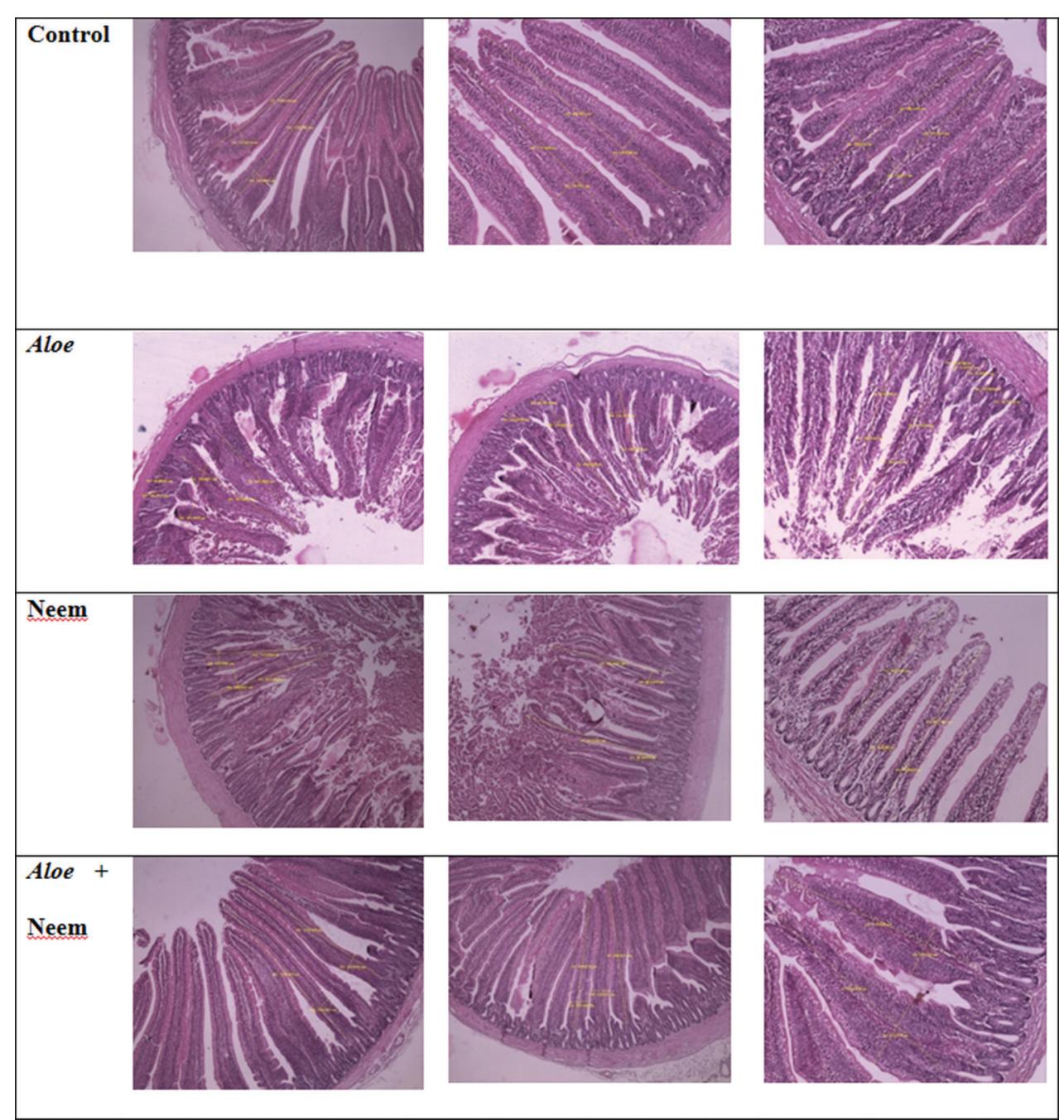

Plate-1: Effect Aloe and neem water additives on gut histomorphometry in Vanaraja chicks.

of illeum segment. The results of present study are in agreement with the report of Homan et al. [17], Kadhim et al. [18] that longer villi is essential to animal development because it would result in an increased surface area for absorption of nutrients [19]. Accordingly, the significantly higher ratio of villus height: Crypt depth in the present study indicated that Aloe and neem supplementation has made the gut environment free of microbial toxins [20]. Short-chain fatty acids produced by Lactobacillus sps. in that intestine are responsible for favorable change in intestinal morphology and might have stimulated the proliferation of epithelial cells of the bowel [21]. In addition, lower crypt depth with Aloe and neem supplementation indicated for slow tissue turnover preventing the pathogens from tissue destruction in the gut [20].

\section{Conclusion and Recommendation}

Based on this comprehensive study, it is concluded that immediate post hatch supplementation of extracts of Aloe and neem in the water of Vanaraja chicks enhanced the gut health and gut development. The $A$. vera and $A$. indica might be promising replacers to antibiotic growth promoters for organic poultry production.

\section{Authors' Contributions}

TS contributed in designing of experiment extraction and feeding experiment in poultry. SA did the feeding experiment, monitoring of the experimental birds. JS did the microbial analysis of gut flora. MT did the histopathological analsyis of gut tissues. AK did the analysis and overall monitoring of the experiment and preparation of manuscript. All authors read and approved the final manuscript.

\section{Acknowledgments}

The authors are grateful to the Director, Central Agricultural Research Institute for providing the facilities and financial assistance to carry out this work.

\section{Competing Interests} interests.

The authors declare that they have no competing

\section{References}

1. Arunkumar, S. and Muthuselvam, K. (2009) Analysis of phytochemical constituents and antimicrobial activities of Aloe vera L. Against clinical pathogens. World J. Agric. Sci., 5: 572-576.

2. Devakumar, C. and Suktt, D.V. (1993) Chemistry. In: Randhawa, N.S. and Parmar, B.S, editors. Neem Research 
and Development. Publication No. 3. Society of Pesticide Science, India. p63-96.

3. Hernandez, F., Madrid, J., Garcia, V., Orengo, J. and Megias, M.D. (2004) Influence of two plant extracts on broilers performance, digestibility, and digestive organ size. Poult. Sci., 83: 169-174.

4. Tariq, H., Rao, P.V.R., Mondal, B.C. and Malla, B.A. (2014) Effect of Aloe vera (Aloe barbadensis) and Clove (Syzigium aromaticum) Supplementation on immune status, haematological and serum biochemical parameters in Japanese quails. Indian J. Anim. Nutr., 31: 293-296.

5. Mahfuzul, H.M.D., Bari, M.L., Inatsu, Y., Juneja, V.K. and Kawamoto, S. (2007) Antibacterial activity of guava (Psidium guajava L.) and neem (Azadirachta indica A. Juss.) extracts against foodborne pathogens and spoilage bacteria. Foodborne Pathog. Dis., 4: 481-488.

6. EI-Mahmood, A.M., Ogbonna, O.B. and Raji, M. (2010) The antibacterial activity Azadirachta indica (neem) associated with eye and ear infections. J. Med. Plant Res., 4: 1414-1421.

7. Jawad, Z., Younus, M., Rehman, M., Maqbool, A., Munir, R., Muhammad, K., Korejo, K.A. and Qazi, I.H. (2013) Effect of neem leaves (Azadirachta indica) on immunity of commercial broilers against new castle disease and infectious bursal disease. Afr. J. Agric. Res., 8: 4596-4603.

8. Kanduri, A.B., Saxena, M.J., Ravikanth, K., Maini, S. and Kokane, S.S. (2013) Effect of dietary replacement of antibiotic growth promoter with herbal growth promoter on performance of broiler poultry birds. Int. J. Appl. Pharm. Sci. Bio. Med. Sci., 2: 12-15.

9. Bancroft, J.D. and Marilyn, G. (2008) Theory and Practice of Histological Techniques. $6^{\text {th }}$ ed. Churchill Livingstone Elsevier, Philadelphia, PA.

10. Petrie, A. and Watson, P. (1991) Statistics for Veterinary and Animal Sciences. Blackwell Science, Malden, MA.

11. Snedecor, G.W. and Cochran, W.G. (1994) Statistical Methods. $8^{\text {th }}$ ed. IOWA State University Press, Ames, IOWA, USA.

12. Saki, A.A., Harcini, R.R., Rahmatnejad, E. and Salary, J.
(2012) Herbal additives and organic acids as antibiotic alternatives in broiler chickens diet for organic production. Afri. J. Biotechnol., 11: 2139-2145.

13. Nayaka, H.B.S., Umakantha, B., Ruban, S.W., Murthy, H.N.N. and Narayanaswamy, H.D. (2012) Effect of neem, turmeric, vitamin $\mathrm{E}$ and their combinations on immune response in broilers. Glob. Vet., 9: 486-489.

14. Stanley, M.C., Ifeanyi, O.E. and Eziokwu, O.G. (2014) Antimicrobial effects of Aloe vera on some human pathogens. Int. J. Curr. Microbiol. Appl. Sci., 3: 1022-1028.

15. Mohammadmehdi, F. and Jamshid, K. (2012) Inhibitory activity of Aloe vera gel on some clinically isolated cariogenic and periodontopathic bacteria. J. Oral Sci., 54(1): 15-21.

16. Poonam, P., Himani, B. and Shivangi, M. (2013) Azadirachta indica (Neem): Antibacterial effects against Escherichia coli and Salmonella guru drone. J. Pharm. Res., 1: 18-21.

17. Homan, I., Javad, A., Abolghasem, G. and Mohammad, R.R. (2013) Effects of chicory root powder on growth performance and histomorphometry of jejunum in broiler chicks. Vet. Res. Forum, 4: 169-174.

18. Kadhim, K.K., Zuki, A.B.Z., Noordin, M.M., Babjee, S.M.A. and Zamri-Saad, M. (2012) Histomorphometric evaluation of small intestinal mucosa of red jungle fowl and commercial broiler from one day to four months of age. Afri J Biotechnol., 11: 1806-1811.

19. Moghaddam, H.N. and Alizadeh-Ghamsari, A.H. (2013) Improved performance and small intestinal development of broiler chickens by dietary L-glutamine supplementation. J. Appl. Anim. Res., 41: 1-7.

20. Ghazanfari, S.I., Mohammadi, Z.I. and Moradi, M.I.I. (2015) Effects of Coriander essential oil on the performance, blood characteristics, intestinal microbiota and histological of broilers. Braz. J. Poult. Sci., 17: 419-426.

21. Olnood, C.G., Beski, S.S.M., Choct, M. and Iji, P.A. (2015) Novel probiotics: Their effects on growth performance, gut development, microbial community and activity of broiler chickens. Anim. Nutr., 1: 184-191. 